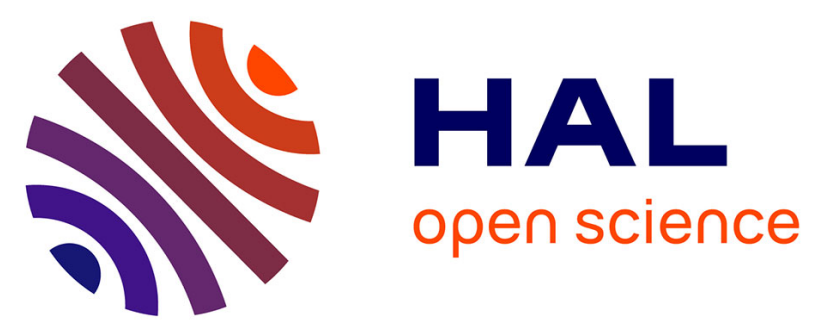

\title{
Mechanical Properties Enhancement while Decreasing the Viscosity of Copolyether-Ester from In Situ Formation of Star-Based Structures by Reactive Extrusion
}

Antoine Lucas, Adrien Tauleigne, Fernande da Cruz-Boisson, Agnès Crepet, Aurélie Bergeron-Vanhille, Grégory Martin, Nicolas Garois, Philippe

Cassagnau, Véronique Bounor-Legaré

\section{To cite this version:}

Antoine Lucas, Adrien Tauleigne, Fernande da Cruz-Boisson, Agnès Crepet, Aurélie BergeronVanhille, et al.. Mechanical Properties Enhancement while Decreasing the Viscosity of CopolyetherEster from In Situ Formation of Star-Based Structures by Reactive Extrusion. Industrial and engineering chemistry research, 2020, 59 (38), pp.16579-16590. 10.1021/acs.iecr.0c02801 . hal-03007715

\section{HAL Id: hal-03007715 https://hal.science/hal-03007715}

Submitted on 6 Jan 2021

HAL is a multi-disciplinary open access archive for the deposit and dissemination of scientific research documents, whether they are published or not. The documents may come from teaching and research institutions in France or abroad, or from public or private research centers.
L'archive ouverte pluridisciplinaire HAL, est destinée au dépôt et à la diffusion de documents scientifiques de niveau recherche, publiés ou non, émanant des établissements d'enseignement et de recherche français ou étrangers, des laboratoires publics ou privés. 


\title{
Mechanical properties enhancement while decreasing viscosity of copolyether-ester from in situ formation of star-based structures by reactive extrusion
}

\author{
A. Lucas ${ }^{\mathrm{a}}$, A. Tauleigne ${ }^{\mathrm{a}}$, F. Da Cruz Boisson ${ }^{\mathrm{b}}$, A. Crépet ${ }^{\mathrm{a}}$, A. Vanhille \\ Bergeronc, G. Martin ${ }^{c}$, N. Garoisc, P. Cassagnau ${ }^{a}$, V. Bounor-Legaréa* \\ a- Univ Lyon, Université Lyon1, CNRS UMR 5223, Ingénierie des Matériaux Polymères, F-69622, \\ LYON, France \\ b- Univ Lyon, INSA de Lyon, CNRS UMR 5223, Ingénierie des Matériaux Polymères, F-69621, LYON, \\ France \\ c-Hutchinson, Centre de Recherche, Rue Gustave Nourry - B.P. 31, 45120, Chalette-sur-Loing, \\ France \\ *Email :bounor@univ-lyon1.fr
}

\begin{abstract}
Blends of a copolyether-ester thermoplastic with different multifunctional (mono-, di- and tri) amine-terminated polyethers have been carried out by reactive extrusion. The reaction with polyetheramine Jeffamine T-403 allows to reduce drastically the viscosity of the blends, while in the same time improving the Young's modulus of the matrix up to 30\% and keeping elongation at break around $700 \%$ and stress at break around $20 \mathrm{MPa}$. The mechanism and the structures deeply scrutinized by NMR (in particular 2D DOSY), chromatography and mass spectrometry evidenced the in situ formation of star-shaped based structures. These complex structures are responsible of these changes in rheological and mechanical behaviors. This onestep approach represents an efficient and relevant way to enhance some mechanical properties while favoring the flow behavior of these copolyether-esters.
\end{abstract}




\section{Introduction}

Decreasing the melt viscosity of the polymers while keeping high levels of mechanical properties is an essential axis of research. Indeed, a low melt viscosity allows a reduction of the energy used to process and inject the polymer. Furthermore, it can bring new application fields to the polymer such as the impregnation of fiber tissues for example. A decrease in viscosity can be reached by simply reducing the molar mass of the polymer, for instance by chain cleavage reactions. However, the side effect of such action is usually also a decrease of the mechanical properties. In order to decrease the melt viscosity while keeping suitable mechanical properties, very interesting results have been reached by using supramolecular polymers.

Actually, this notion was first really introduced by Lehn ${ }^{1,2}$ in 1989 with the synthesis of a liquid crystalline supramolecular polymer by self-assembly of the two complementary monomers uracil and 2,6-diacylamino-pyridine which formed triply hydrogen-bonded pairs.

Then, quadruple hydrogen bonding between the end-groups of the polymers were obtained by T. Long et al..$^{3-8}$ by functionalizing the end-groups of different synthesized polymers of small molar masses with ureidopyrimidinone UPy. This addition was successfully tested onto poly(styrene $)^{3,4}$, poly(isoprene $)^{3}$, poly(butyl acrylate $)^{5}$, poly(butylene terephthalate $)^{6}$, poly(butylene isophthalate $)^{6}$ and star-shaped poly(ethylene-co-propylene) $)^{7,8}$. This resulted in an increase of the mechanical properties of the polymers at room temperature. For example, these modified poly(butylene terephthalate) (PBT) with multiple hydrogen bonding (MHB) units exhibits a $30 \%$ higher impact strength and $400 \%$ higher elongation at break than a PBT with the same molar mass.. This improvement of mechanical properties was coupled with an excellent thermal control of the viscosity. Indeed the H-bonds dissociated for a temperature above $80^{\circ} \mathrm{C}$ and the different polymers recovered the low viscosities of their nonfunctionalized equivalents. More recently, Leibler et al. ${ }^{9}$ were able to synthesize by polycondensation supramolecular semicrystalline telechelic polymers with terminal $\mathrm{H}$ bonding groups and presenting an impressive viscosity of less than 1 Pa.s above their melting point. At room temperature, their ability to crystallize allowed them to present interesting mechanical properties with, for example, stress at break values between 5 and $12 \mathrm{MPa}$.

These works certainly showed impressive results on the thermo-reversibility of H-bonding and the low melt viscosity it allows at high temperature. However, excepting for a few articles, the mechanical properties of the created polymers were not extensively studied. 
Moreover, the synthesis of these oligomers can be complex, and the scale-up of the process can quickly become very complicated and expensive.

Another way to obtain a significant decrease in viscosity coupled with a relative conservation of the mechanical properties is to blend a matrix with dendrimers, star-shaped or hyperbranched polymers (HBP). Unlike dendrimers, HBP can be produced in industrial quantities at low cost and still inherit the interesting properties of dendrimers. Such polymers have been first used as additives in 1992 by Kim and Webster ${ }^{10}$ who observed the decrease in viscosity induced when HBP were mixed with linear polymers. Highly branched polyphenylenes were blended with linear polystyrene, and despites the poor compatibility, the viscosity of the blend with $5 \%$ wt of polyphenylene was lower to about $50 \%$ at $180{ }^{\circ} \mathrm{C}$ and $80 \%$ at $220{ }^{\circ} \mathrm{C}$, while keeping good tensile modulus. Hyperbranched polyesters have been widely used as processing aids for linear polymers. Hong et al. ${ }^{11}$, Jang et al. ${ }^{12}$ and Mulkern et al. ${ }^{13}$ all developed polymer/hyperbranched polyesters systems and witnessed a decrease of the polymer viscosity. This decrease is due to the compact structure of the HBP which adopts a sphere-like hydrodynamic volume in solution or in the melt. This results in a decrease of the chain entanglement which allows polymers to flow past each other more easily under applied stress. Moreover, the high density of functional terminal groups on the HBP can improve the miscibility of the additive and the polymer. Many other studies have been made on various $\mathrm{HBP} /$ polymer blends ${ }^{14-16}$, but once again, in all these works, mechanical properties of the final blends have been poorly studied. Moreover, in the majority of these studies, the branched polymers are used as rheology modifiers and processing aids, where $\mathrm{H}$-bonding is the only chemical interaction witnessed when a decrease of viscosity takes place. In the case where covalent bonds are created between the branched additive and the matrix, a chain-extension mechanism occurs and the viscosity increases drastically ${ }^{17}$. A last cited example of blend is the one from Leibler et al. ${ }^{18}$ who were able to lower the viscosity of an amorphous biosourced polyamide (PA) resin to less than $10 \mathrm{~Pa}$.s while increasing its elastic modulus from $4 \mathrm{MPa}$ to $30 \mathrm{MPa}$ by mixing it with $10-50 \%$ wt of a small supramolecular polymer. This additive was able to partially crystallize and thus reinforce the amorphous PA at room temperature, while acting as a plasticizer in the molten state and reducing the viscosity of the PA. Besides, all these examples represented a two-steps approach with first the synthesis of the additive and then the blending with the main matrix.

To our knowledge, a significant decrease in viscosity coupled with an enhancement of the mechanical properties has never been reached for any polymer by a one-step reactional based 
approach. Thus, in the present study, we propose a new method to obtain a decrease of viscosity coupled with an increase of mechanical properties on a copolyether-ester matrix (COPE) by reactive extrusion with an amine-terminated polyether. These COPE have been widely studied industrially and in the literature because of their excellent flex fatigue resistance and broad temperature usage range. They resist tearing, flex-cut growth, creep, abrasion, and exhibit a very good toughness while resisting to hydrocarbons and many other fluids. In a first part we will present the rheological and mechanical results obtained for reactive blends of COPE and polyetheramines of different molar masses and functionalities. In a second part, the more promising systems regarding their properties were chemically characterized by different specific NMR techniques, MALDI-TOF mass spectrometry and SEC-MALLS.

\section{Materials and blends preparation}

\subsection{Polymer and additives}

The Keyflex BT-1055D matrix (COPE) from LG Chem was kindly supplied by Hutchinson Research Center. It is a copolyether-ester thermoplastic elastomer with a $\mathrm{M}_{\mathrm{n}}=30000 \mathrm{~g} \cdot \mathrm{mol}^{-1}$ determined by size exclusion chromatography (SEC). Its chemical structure was characterized by NMR (Figure S1) and is presented in Figure 1. This polymer is a copolyether-ester composed of semi-crystalline poly(butylene terephthalate) (PBT) and amorphous poly(tetramethylene oxide) (PTMO) blocks. The average number of oxybutylene units in a PTMO block is 11.7 and the molar ratio between the two blocks PBT/PTMO is 7.2:1. COPE presents a melting point of $206^{\circ} \mathrm{C}$.

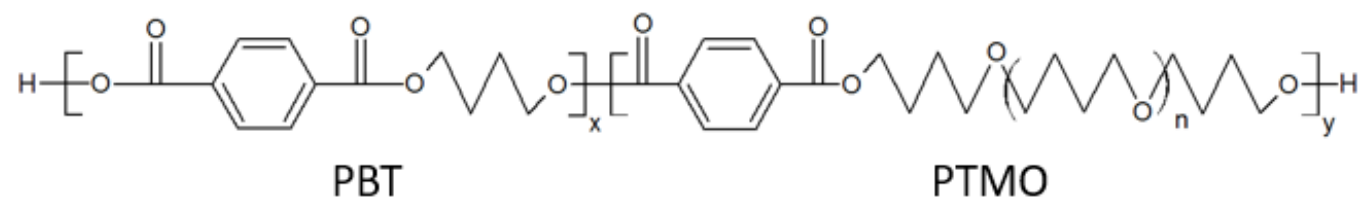

Figure 1: Chemical structure of the COPE matrix $(x=0.9, y=0.1, n=9.7)$

PBT used as a reference to demonstrate the effect of the amine on the PBT blocks of the COPE was a PBT Crastin S600F40 NC010 commercialized by DuPont. 
The different Jeffamine polyetheramines from Huntsman were supplied by Hutchinson Research Center. Their chemical structures and molar masses were determined by NMR and are presented in Table $\mathbf{1 .}$

Table 1: Chemical structures and characteristics of the different amine compounds

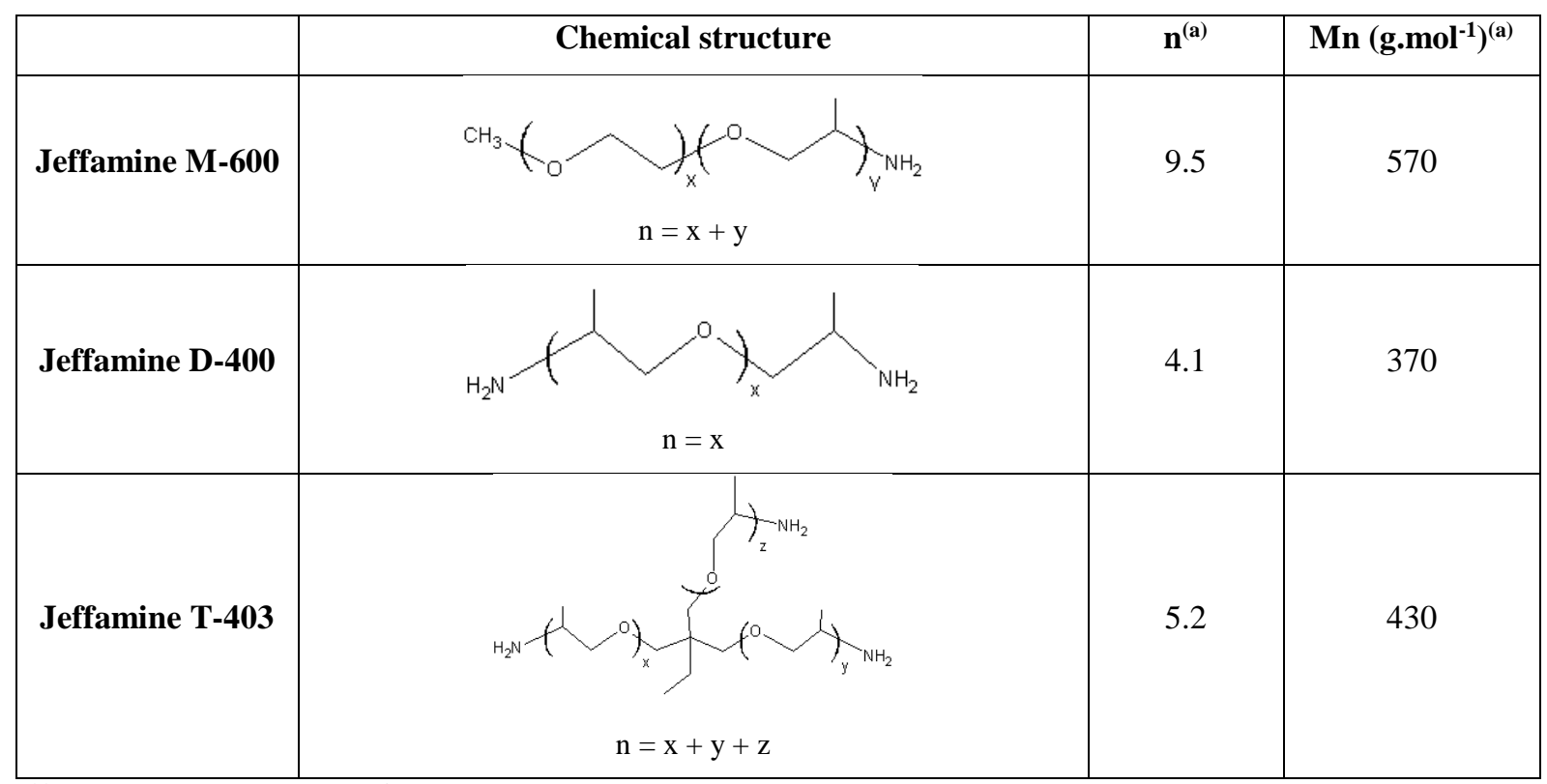

(a) Values calculated from ${ }^{1} \mathrm{H}$ NMR spectra recorded in $\mathrm{CDCl}_{3}$ at room temperature

\subsection{Preparation of the reactive blends}

COPE pellets were dried for $15 \mathrm{~h}$ at $80{ }^{\circ} \mathrm{C}$ under vacuum in order to remove residual water. The different formulations were prepared by melt blending in a co-rotating twin-screw extruder (Leistriz LSM model, diameter $34 \mathrm{~mm}$, L/D 34) at $220{ }^{\circ} \mathrm{C}$. The twin-screw profile is presented in Figure 2. It particularly contains two reverse conveying elements which promote an important shearing during the extrusion process.

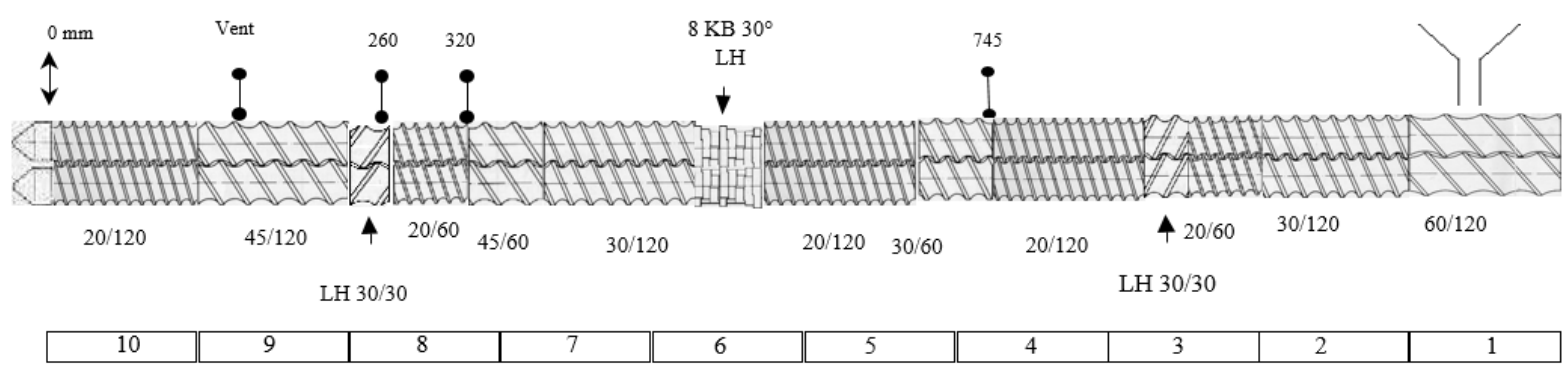

Figure 2: Twin-screw profile with two left-handed conveying elements 
COPE was incorporated by the hopper and processed at a flow of $3 \mathrm{~kg} \cdot \mathrm{h}^{-1}$ with a screw speed of $200 \mathrm{rpm}$. Jeffamine M-600, D-400 and T-403 were heated at $80{ }^{\circ} \mathrm{C}$ to reduce their viscosity and incorporated into the COPE matrix in the molten state at the block $4(\mathrm{~L} / \mathrm{D}=14)$ at a constant flow rate using an external liquid pump in order to maintain the chosen mass percentage of the blend (Table 2). The mean residence time of the polymer in the extruder was measured at around 90s using colored pellets.

Table 2: Molar concentration of reactive functions for the different COPE/Jeffamine blends $\left(\mathrm{mol}^{\mathrm{k}} \mathrm{kg}^{-1} \mathrm{of} \mathrm{COPE}\right)$

\begin{tabular}{|c|c|c|c|c|}
\hline Reactive blend & Additive composition $(\% \mathbf{w t})$ & {$[\mathbf{C O O H}] \mathbf{C O P E}$} & {$\left[\mathbf{N H}_{2}\right]$ added } & {$\left[\mathbf{N H}_{2}\right] /[\mathbf{C O O H}]$} \\
\hline COPE & 0 & 0.033 & 0 & 0 \\
\hline \multirow{3}{*}{ COPE + M-600 } & 2 & 0.033 & 0.035 & 1.06 \\
\cline { 2 - 5 } & 4 & 0.032 & 0.070 & 2.19 \\
\cline { 2 - 5 } & 6 & 0.031 & 0.105 & 3.39 \\
\hline \multirow{3}{*}{ COPE + D-400 } & 8 & 0.031 & 0.140 & 4.52 \\
\cline { 2 - 5 } & 1.5 & 0.033 & 0.081 & 2.45 \\
\cline { 2 - 5 } & 3 & 0.032 & 0.162 & 5.06 \\
\hline \multirow{3}{*}{ COPE + T-403 } & 4.5 & 0.032 & 0.243 & 7.59 \\
\cline { 2 - 5 } & 1 & 0.033 & 0.070 & 2.12 \\
\cline { 2 - 5 } & 2 & 0.033 & 0.140 & 4.24 \\
\cline { 2 - 5 } & 3 & 0.032 & 0.210 & 6.56 \\
\cline { 2 - 5 } & 5 & 0.032 & 0.350 & 10.94 \\
\hline
\end{tabular}

PBT/T-403 reference blends were mixed with an internal Haake mixer Rheomix OS (Thermo Fisher Scientific) at $220{ }^{\circ} \mathrm{C}$ with a rotor speed of $50 \mathrm{rpm}$ for $20 \mathrm{~min}$, time for which we observe a good stabilization of the measured torque.

\section{Methods of characterization}

\subsection{NMR spectroscopy}

$1 \mathrm{D}-{ }^{1} \mathrm{H}, 2 \mathrm{D}$ COSY, HMBC and HSQC and DOSY spectra were recorded at $\mathrm{T}=300 \mathrm{~K}$ using standard sequences on a Bruker Avance-III spectrometer equipped with a $5 \mathrm{~mm}$ BBFO+ probe operating at $400.1 \mathrm{MHz}$ for ${ }^{1} \mathrm{H}$. $1 \mathrm{D}-{ }^{13} \mathrm{C}$ NMR spectra were recorded in the same 
conditions on a Bruker Avance-II spectrometer equipped with a $10 \mathrm{~mm}{ }^{13} \mathrm{C}$ selective probe operating at $100.6 \mathrm{MHz}$ for ${ }^{13} \mathrm{C}$. The different amine compounds were analyzed in $\mathrm{CDCl}_{3}$ while all the COPE/amine blends were analyzed in a mixture of hexafluoroisopropanol (HFIP)/CDCl $3(80: 20 \mathrm{v} / \mathrm{v})$ with typical concentrations of $20 \mathrm{mg} \cdot \mathrm{mL}^{-1}$ for $1 \mathrm{D}-{ }^{1} \mathrm{H}$ analysis and $70 \mathrm{mg} \cdot \mathrm{mL}^{-1}$ for $1 \mathrm{D}^{-13} \mathrm{C}$ and $2 \mathrm{D}$ COSY, HMBC and HSQC analysis. Chemical shifts were referenced to tetramethylsilane (TMS, $\delta=0 \mathrm{ppm}$ ). For 2D ${ }^{1} \mathrm{H}$-DOSY experiments, a double stimulated echo sequence with bipolar gradient pulses (dgste-bp) was employed for selfdiffusion coefficients measurement, and the samples were analyzed in a mixture of HFIP$\mathrm{d}_{2} / \mathrm{CDCl}_{3}(80: 20 \mathrm{v} / \mathrm{v})$ with a concentration of $20 \mathrm{mg} \cdot \mathrm{mL}^{-1}$. Gradients were incremented from $0.96 \mathrm{G} . \mathrm{cm}^{-1}$ to $47,19 \mathrm{G} . \mathrm{cm}^{-1}$ in 40 steps using an exponential ramp, diffusion time and gradient duration were adjusted for each. NMR results were processed on Topspin 3.5 software (Bruker).

\subsection{Size Exclusion Chromatography (SEC) with a conventional calibration or a Multi-Angle Light Scattering detector (MALLS)}

Molar masses of the different formulations were determined by SEC on a device composed of one PLgel $20 \mu \mathrm{m}$ Guard 50x7.5 mm pre-column (Agilent), two PLgel $5 \mu \mathrm{m}$ Mixed-C 300x7.5 $\mathrm{mm}$ columns (polystyrene/divinylbenzene) (Agilent), a Perkin Elmer Series 200 pump injector, a LC-20AD pump (Shimadzu) and a RID-10A differential refractive index detector (Shimadzu). Polystyrene conventional calibration was used to determine the average molar masses of the compounds.

SEC was also coupled with a multi-angle light scattering (MALLS) detector (TREOS 3 angles, Wyatt) and a refractometer RID 10A (Shimadzu) to determine the average molar masses. Differential index of refraction $\mathrm{dn} / \mathrm{dc}$ of $0.13 \mathrm{ml} . \mathrm{g}^{-1}$ used in the data processing was measured with the Wyatt Optilab T-rex $(\lambda=658 \mathrm{~nm})$ refractometer.

For both SEC, with a conventional calibration or MALLS detector, solutions with a concentration of $1 \mathrm{mg} \cdot \mathrm{mL}^{-1}$ were prepared in a mixture of $\mathrm{CHCl}_{3} / \mathrm{HFIP}(98: 2 \mathrm{v} / \mathrm{v})$, filtrated with polytetrafluoroethylene (PTFE) $0.45 \mu \mathrm{m}$ filters and eluted in the columns with $\mathrm{CHCl}_{3}$ at a flow of $1 \mathrm{ml} \cdot \mathrm{mn}^{-1}$. 


\subsection{MALDI-TOF mass spectrometry}

T-403 and COPE + 10\%wt T-403 samples were solubilized in $\mathrm{CHCl}_{3}$ at 10 g.L ${ }^{-1}$. The dithranol matrix was also solubilized in $\mathrm{CHCl}_{3}$ at $10 \mathrm{~g} . \mathrm{L}^{-1}$. A volume of $9 \mu \mathrm{L}$ matrix solution was then mixed with $1 \mu \mathrm{L}$ of sample solution. An aliquot of $1 \mu \mathrm{L}$ of each resulting solution was spotted onto the MALDI sample plate and air-dried at room temperature. All mass spectra were acquired with a Voyager-DE Pro (AB Sciex, Framingham, MA) with a final tension of $20 \mathrm{kV}$, operating in the linear or reflectron mode. An external mass calibration of mass analyzer was used (mixture of peptides from Sequazyme ${ }^{\mathrm{TM}}$ standards kit, AB Sciex). The positive ions were detected in all cases.

\subsection{Rheological characterization}

Dynamic frequency tests were conducted on a strain-controlled ARES Rheometer (TA Instruments) using a parallel plate geometry (25 mm diameter, $0.95 \mathrm{~mm}$ gap). Cylindrical samples ( $25 \mathrm{~mm}$ diameter, $1 \mathrm{~mm}$ thickness) were prepared with a bench type press Polystat $200 \mathrm{~T}$ (Servitec) and measurements were performed at $220^{\circ} \mathrm{C}$ to determine the complex shear modulus (storage modulus $\left(G^{\prime}\right)$ and loss modulus $\left(G^{\prime \prime}\right)$ ) and the absolute complex viscosity $\left(\left|\eta^{*}\right|\right)$ by varying the frequencies from 100 to $0.01 \mathrm{rad}^{-1}{ }^{-1}$.

\subsection{Mechanical characterization}

Uniaxial traction measurements were performed at room temperature on bone shaped $\mathrm{H} 2$ tensile samples on a MTS Criterion Model 43 machine (MTS Systems Corporation) equipped with a $500 \mathrm{~N}$ force sensor. After being dried $15 \mathrm{~h}$ at $80{ }^{\circ} \mathrm{C}$ under vacuum, extruded pellets of the different formulations were injected into bone shaped $\mathrm{H} 2$ samples on a hydraulic injection molding machine Babyplast 6/10P equipped with a piston diameter of $14 \mathrm{~mm}$ and presenting a clamping force of $62 \mathrm{kN}$. Chamber temperature was $220{ }^{\circ} \mathrm{C}$, mold temperature $40{ }^{\circ} \mathrm{C}$, and the injection pressure was adapted to each type of sample in order to provide the optimal filling of the mold. The deformation speed was $2 \mathrm{~mm} \cdot \mathrm{min}^{-1}$ for the measurement of Young's modulus, and $30 \mathrm{~mm} \cdot \mathrm{min}^{-1}$ for the measurement of yield strength, breaking strength and elongation at break. At least 6 different samples were tested for each formulation, with a standard deviation under $10 \%$.

\section{Results and discussion}


The impact of the reaction between mono-, di- and tri-amine and the COPE through reactive extrusion on the rheological behavior and mechanical properties at room temperature was first evaluated and then in a second part related to the specific created structures during the extrusion process.

\subsection{Rheological and mechanical properties of the modified COPE}

First, Figure 3a-c shows the variation of the absolute complex viscosities versus frequency in the molten state $\left(\mathrm{T}=220^{\circ} \mathrm{C}\right)$ for different blends obtained by reaction between the COPE with M-600, D-400 and T-403 respectively. 
a)

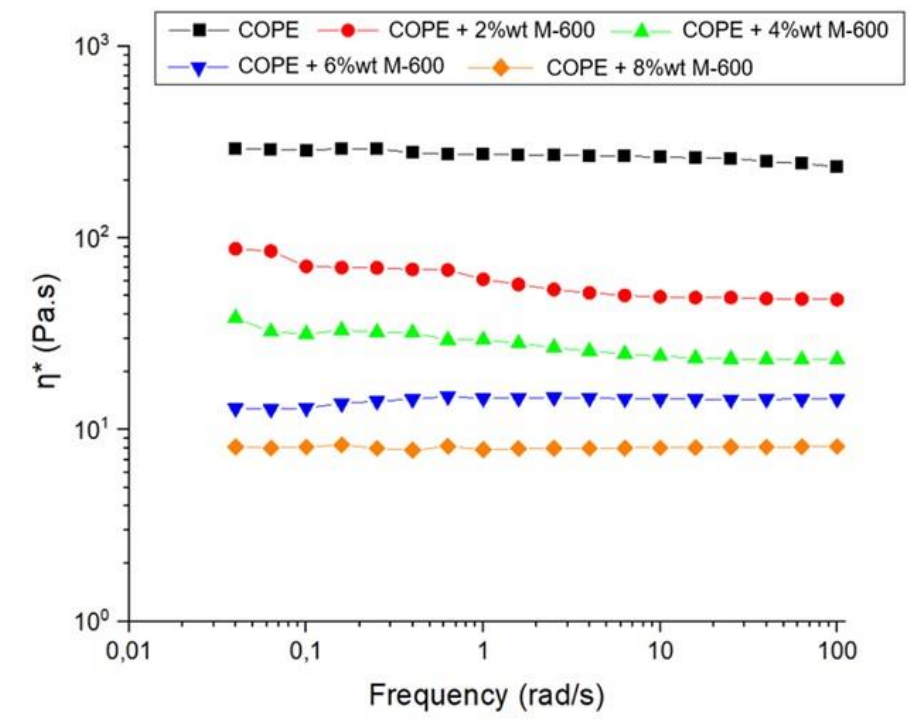

b)

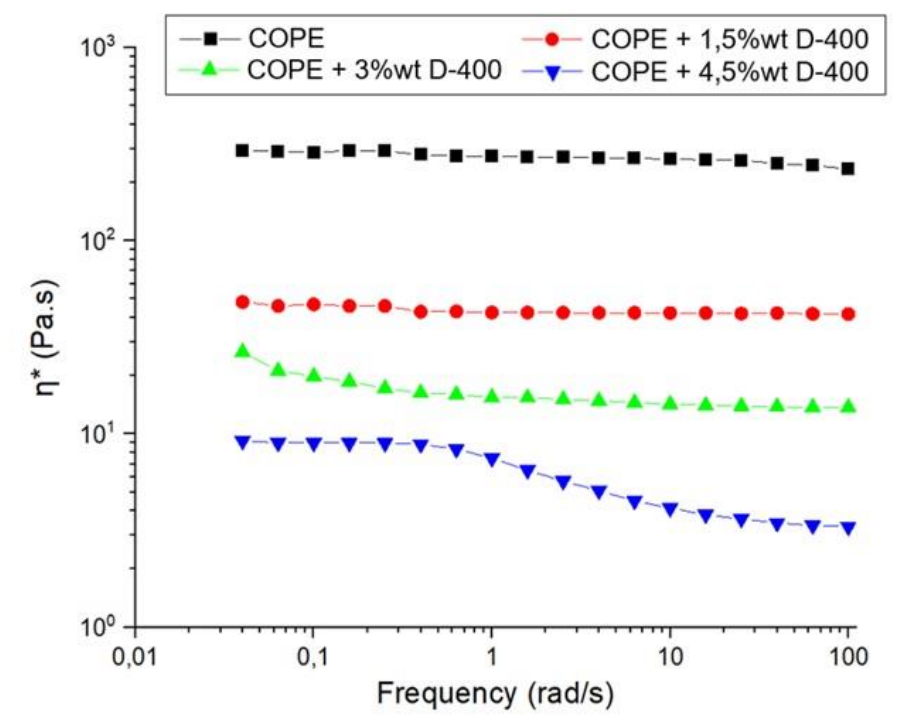

c)

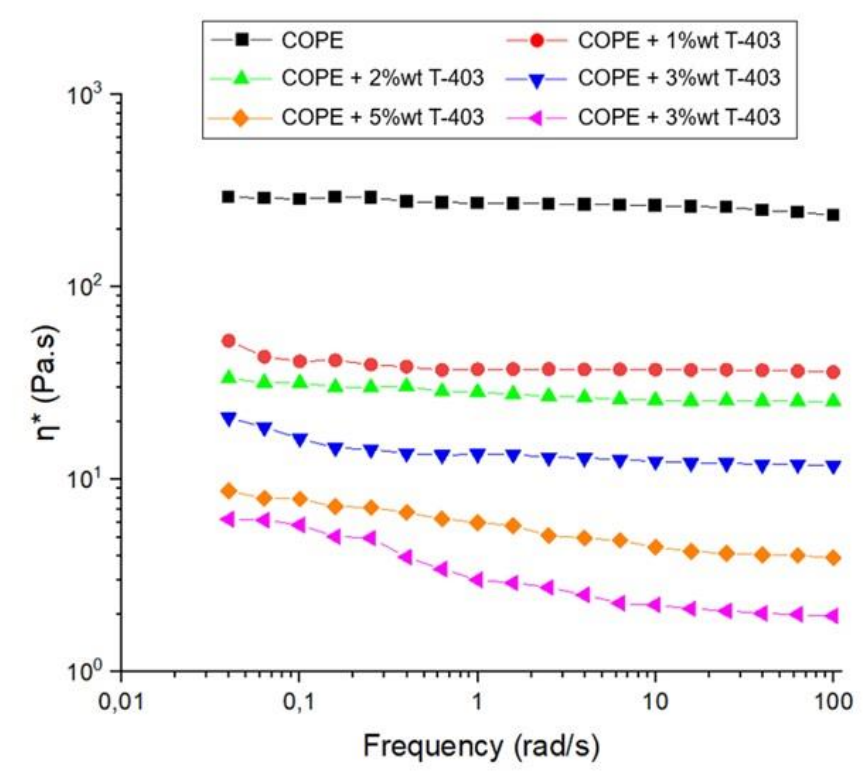


Figure 3: Variation of the absolute complex viscosity versus frequency $\left(\mathrm{T}=220^{\circ} \mathrm{C}\right)$ a) $\left.\mathrm{COPE} / \mathrm{M}-600 \mathrm{blends}, \mathrm{b}\right)$ COPE/D-400 blends, c) COPE/T-403 blends

These figures clearly show that any of the addition of the Jeffamine M-600, D-400 and T-403 lead to an important decrease of the COPE viscosity depending on the concentration of the amine additive. These decreases of viscosity are associated to a decrease of the average molar mass of the polymer as shown in Figure 4.

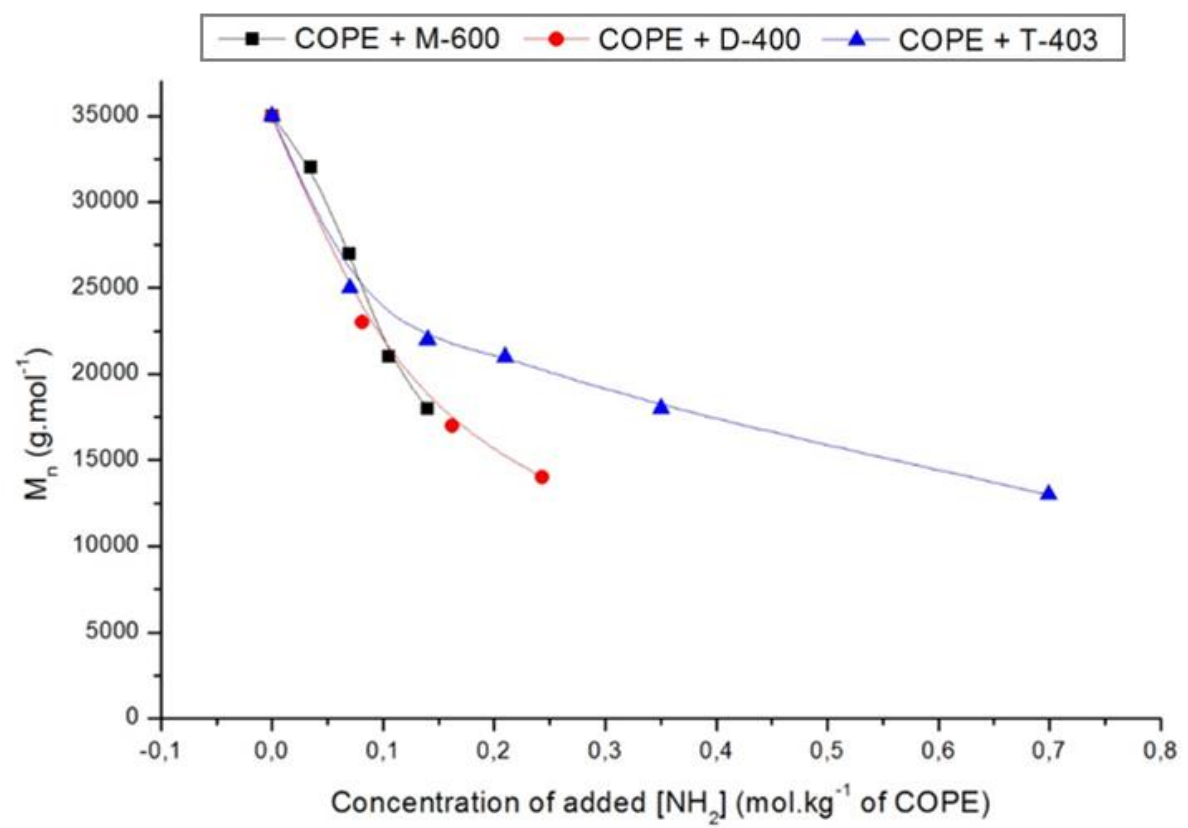

Figure 4: Variation of the average molar masses versus amine concentration for COPE/M-600, COPE/D-400 and COPE/T-403 blends

The molar masses variations are mainly due to the chain cleavage caused by a reaction of the COPE with the different Jeffamines. More precisely, this chain cleavage is caused by a classical substitution reaction on the ester groups of the PBT blocks, as confirmed with the rheological analysis of PBT/T-403 blends (from 1 to 3\%wt of T-403). In the Figure S2 we observe for this reference blend the same rheological behavior as for the COPE/T-403 systems, with a decrease of the complex viscosity above $10^{2}$ Pa.s for 2 and $3 \%$ wt of T-403, which highlight that the attack of the amino groups likely took place on the ester groups of the PBT blocks through a nucleophilic substitution.

For the blends of COPE with M-600 and D-400, we can notice in Figure 4 that for a same concentration of added amine groups the decrease of molar mass is rather similar evidencing a similar reactivity for these amino groups. The behavior is different for the COPE/T-403 blends. This could traduce a poorer reactivity of the third amine group due to steric hindrance, 
or a poorer miscibility of COPE and T-403 when high T-403 quantities are added. Indeed AFM analysis (shown in Figure S3) revealed the presence of droplets of T-403 at the surface of the blends of COPE with 5\%wt of T-403 (compared to the observation done on the blend of COPE with $2 \mathrm{wt} \%$ of T-403), indicating a poor miscibility and thus an incomplete reaction of the Jeffamine with the COPE for the highest T-403 concentration.

The mechanical properties of these different blends are reported in Table 3. Note that the melting temperature and the melting enthalpy were measured and that no specific change has been observed.

Table 3: Mechanical properties of the COPE/M-600, COPE/D-400 and COPE/T-403 reactive blends

\begin{tabular}{|c|c|c|c|c|c|}
\hline \multicolumn{2}{|c|}{ Added Jeffamine (\%wt) } & $\begin{array}{c}\text { Young's modulus } \\
\text { (MPa) }\end{array}$ & $\begin{array}{c}\text { Yield strength } \\
\text { (MPa) }\end{array}$ & $\begin{array}{c}\text { Breaking strength } \\
\text { (MPa) }\end{array}$ & $\begin{array}{c}\text { Elongation at break } \\
(\%)\end{array}$ \\
\hline \multirow{3}{*}{ COPE } & 2 & $140 \pm 4$ & $16 \pm 1$ & $35 \pm 2$ & $800 \pm 20$ \\
\cline { 2 - 6 } & 4 & $140 \pm 3$ & $15 \pm 1$ & $29 \pm 1$ & $850 \pm 50$ \\
\cline { 2 - 6 } & 6 & $125 \pm 3$ & $14 \pm 1$ & $26 \pm 1$ & $890 \pm 60$ \\
\cline { 2 - 6 } & 8 & $115 \pm 3$ & $13 \pm 1$ & $23 \pm 2$ & $860 \pm 80$ \\
\hline \multirow{3}{*}{ D-400 } & 1.5 & $155 \pm 4$ & $16 \pm 1$ & $31 \pm 2$ & $780 \pm 100$ \\
\cline { 2 - 6 } & 3 & $155 \pm 2$ & $16 \pm 1$ & $25 \pm 3$ & $\mathbf{5 9 0} \pm \mathbf{1 0 0}$ \\
\hline & $\mathbf{1}$ & $\mathbf{1 8 5} \pm \mathbf{5}$ & $\mathbf{1 7} \pm \mathbf{1}$ & $\mathbf{2 0} \pm \mathbf{3}$ & $\mathbf{7 6 0} \pm \mathbf{1 0 0}$ \\
\cline { 2 - 6 } & $\mathbf{2}$ & $\mathbf{1 7 5} \pm \mathbf{2}$ & $\mathbf{1 8} \pm \mathbf{1}$ & $\mathbf{2 4} \pm \mathbf{3}$ & $14 \pm 4$ \\
\cline { 2 - 6 } & 3 & $200 \pm 4$ & - & $14 \pm 2$ & $7 \pm 1$ \\
\cline { 2 - 6 } & 5 & $195 \pm 8$ & - & $10 \pm 1$ & 7800 \\
\hline
\end{tabular}

Despite the decrease of the molar mass, the addition of M-600 to the COPE led to a conservation of the mechanical properties of the COPE when 2 and 4\%wt were added. Above this concentration however, the Young's modulus and the breaking strength underwent a clear decrease due to a drastic chain cleavage.

The reactive blends of COPE with D-400 exhibit an increase of the Young's modulus of approximately $10 \%$ for the smallest D-400 concentration while the COPE $+4.5 \%$ wt blend was too brittle to be injected into stable traction samples.

For the reactive blends of COPE with T-403, the values in Table 3 clearly indicate a change in mechanical behavior between the blends obtained with the smallest amounts of added T403 ( 1 and 2\%wt) and the most concentrated ones (3 to 5\%wt, the blend with 10\%wt of T-403 was too brittle to form stable traction samples). Indeed the Young's modulus undergoes a 
$30 \%$ increase for the $1 \%$ wt T-403 based blend and a $25 \%$ increase on the $2 \%$ wt T-403 based blend while maintaining a good elongation at break and a similar breaking strength. The introduction of 3\%wt or more of T-403 led to a higher Young's modulus but the elongation at break dramatically decreased and the resulting materials were very brittle.

These data shows that the improvement of the Young's modulus was significantly better for the COPE/T-403 systems than for the COPE/M-600 and COPE/D-400 blends. An optimal concentration around $2 \mathrm{wt} \%$ of T-403 comes out for which the Young's modulus of the COPE matrix is increased while the elongation at break is maintained. Above this concentration, the benefice allowed by the decrease of viscosity of the matrix is counterbalanced by an increase of the chain cleavage phenomenon and the material becomes too brittle. This obvious increase of mechanical properties evolves in the opposite direction with the measured complex viscosities and molar masses. This result indicates a difference between the room temperature behavior and the one observed in the molten state and cannot be due only to the PBT chain cleavage.

\subsection{COPE/T-403 blends structure}

In the molten state, the chain cleavage evidenced by SEC involves a decrease of the complex viscosity because the flow of the polymer is facilitated with smaller chains. The increase of Young's modulus with the addition of T-403 at room temperature was antagonist and indicated that other structures should have been created for specific concentrations. In order to investigate such structures, NMR, SEC-MALLS and MALDI-TOF mass spectrometry analyses were conducted on the COPE/T-403 blends.

\subsubsection{NMR spectroscopy}

${ }^{13} \mathrm{C}$ NMR spectra of concentrated COPE/T-403 blend (10\%wt T-403) is shown in Figure 5 and compared to the one of the neat COPE. It appeared clearly that the signal of the carboxylic acid end-groups of the COPE at $171.1 \mathrm{ppm}$ was no more present in the reactive blend while new signals were detected in the carbonyl area at $178.2 \mathrm{ppm}$ and in the aromatic area at $141.8,133.7,131.5$ and $130.3 \mathrm{ppm}$. Those signals were attributed to amide bonds ${ }^{19}$ coming from a reaction of the amines with the COPE, either by transamidification of the ester groups or by condensation of the amines on the carboxylic acid end-groups of the COPE. 2DHMBC experiments correlate our interpretation (spectra shown in Figure S1). 


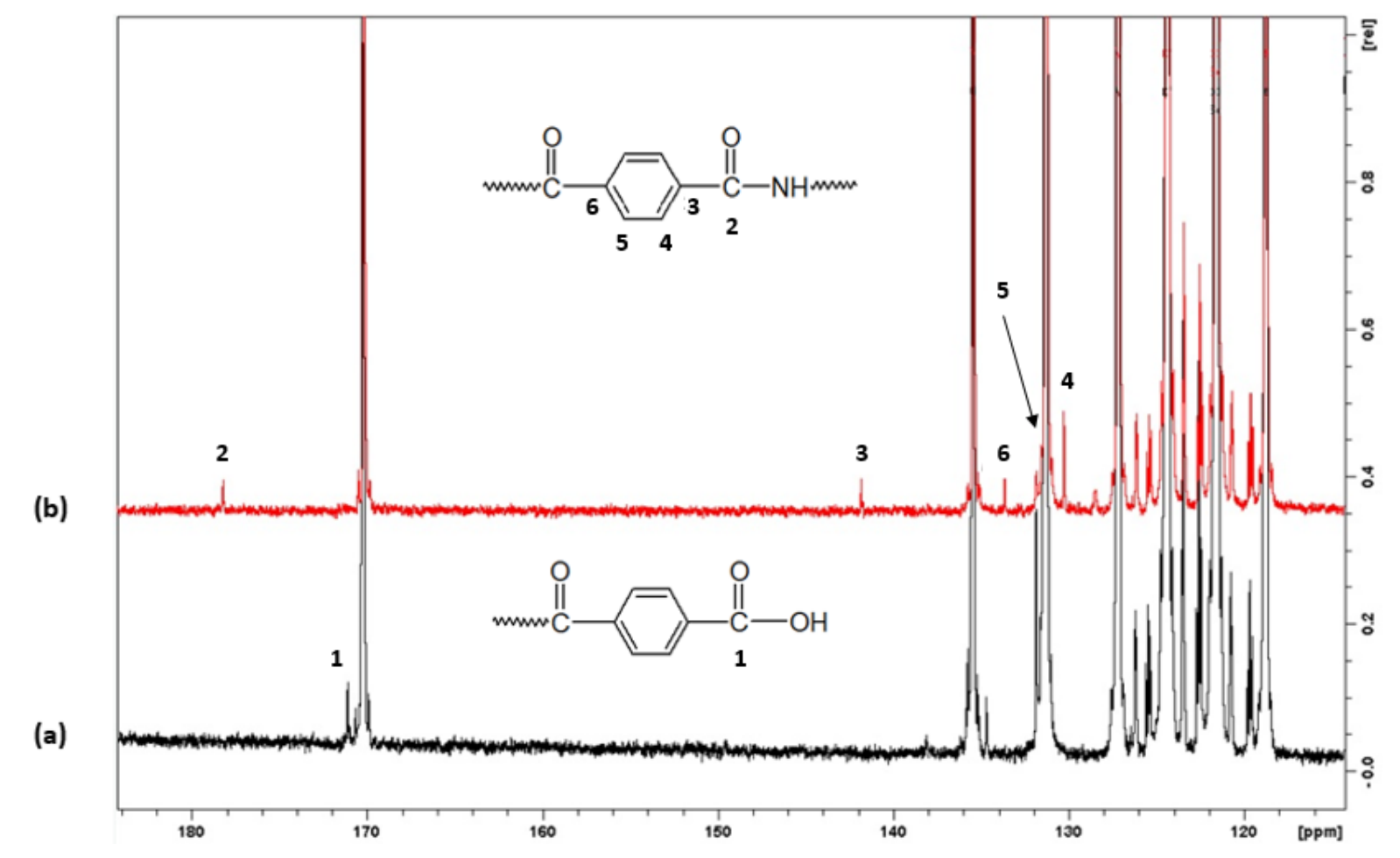

Figure 5: ${ }^{13} \mathrm{C}$ NMR Spectra [115-185 ppm] (a) COPE (b) COPE + 10\%wt T-403 in HFIP/CDCl $(80: 20 \mathrm{v} / \mathrm{v})$

The disappearance of the carboxylic acid end-groups of the COPE and the appearance of the new signals attributed to the creation of amide bonds were also witnessed for the COPE/M600 and COPE/D-400 blends (spectra shown in Figure S4).

${ }^{1} \mathrm{H}$ spectrum of the COPE $+10 \%$ wt T-403 reactive blend shown as the horizontal projection in Figure 6 did not allow to clearly witness the formation of amide groups. However, as some of the NMR signals of the T-403 were well resolved from the resonances of COPE, ${ }^{1} \mathrm{H}-\mathrm{DOSY}$ was used to confirm the covalent bond between the COPE matrix and the T-403. This technique correlates ${ }^{1} \mathrm{H}$ NMR chemical shifts to self-diffusion coefficients of molecules in solution ${ }^{20,21}$ and allows performing a selection on compounds according to their size, which is mainly governed by their molar mass. A double stimulated echo sequence with bipolar gradient pulses was used in order to compensate convection and eddy-current effects ${ }^{22}$.

The resulting 2D DOSY map of the non-reactive solution of neat COPE and 10\%wt of T-403 is shown in Figure 6. 


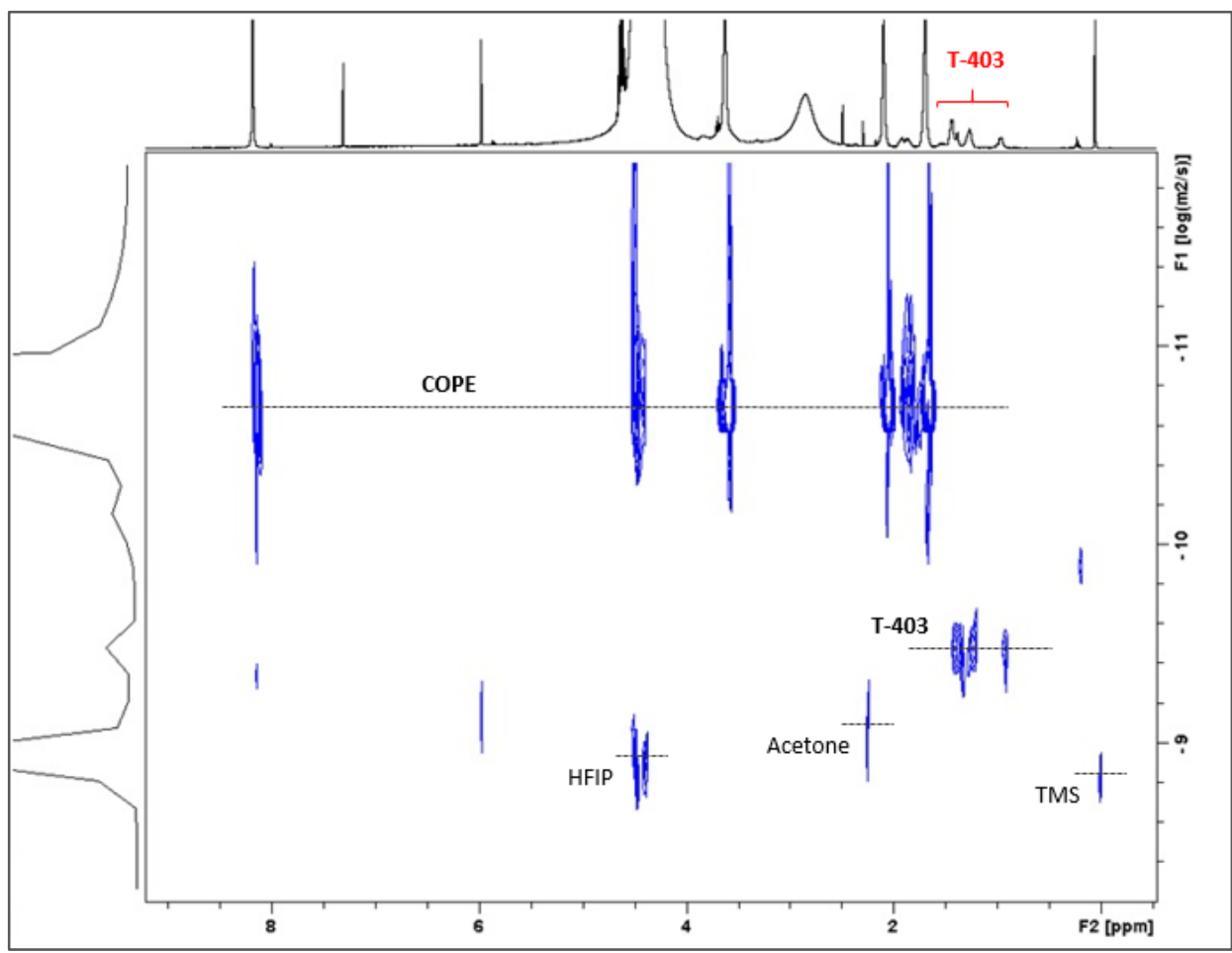

Figure 6: 2D DOSY spectrum of non-reacted COPE + 10\%wt T-403solution in HFIP-d2/CDCl 3 (80:20 v/v).

On this spectrum, despite the broadening of the polymer DOSY signals due to its dispersity, a clear separation was evidenced between the average diffusion coefficient of COPE which mean value was found to be $\mathrm{D}_{\mathrm{C} 0}=2.0 \times 10^{-11} \mathrm{~m}^{2} \cdot \mathrm{s}^{-1}$ and the average diffusion coefficient of $\mathrm{T}-403$ which read value was $\mathrm{D}_{\mathrm{T} 0}=3.3 \times 10^{-10} \mathrm{~m}^{2} . \mathrm{s}^{-1}$.

Diffusion coefficients are determined by using the Stejskal-Tanner equation ${ }^{23,24}$ :

$$
I=I_{0} \cdot \exp \left(-D(\gamma \delta g)^{2} \cdot\left(\Delta-\frac{\delta}{3}-\frac{\tau}{2}\right)\right)
$$

Where $I$ is the attenuated intensity of a signal at a define frequency, $I_{0}$ is the reference intensity of the same signal with $0 \%$ gradient strength, $D$ is the diffusion coefficient, $\gamma$ is the gyromagnetic constant of the hydrogen nucleus, $\delta$ is the gradient pulse length, $g$ is the gradient strength, $\Delta$ is the diffusion delay and $\tau$ is the time between bipolar gradients.

For a single component in a diluted solution, when plotting for each characteristic signal the logarithm of the normalized signal attenuation $\left(\ln \left(\mathrm{I}_{\mathrm{I}}\right)\right)$ versus the square root of the gradient strength, a straight line which slope is proportional to (-D) should be obtained.

To plot those curves for the non-reacted blend, we selected only the resonances of both COPE and T-403 that were not overlapping to follow the signal attenuation: signals at 1.27, 1.38, 
and $1.44 \mathrm{ppm}$ were integrated together to characterize the triamine T-403 and the signal at 2.04 ppm was chosen for the COPE. The resulting curves are presented in Figure 7.

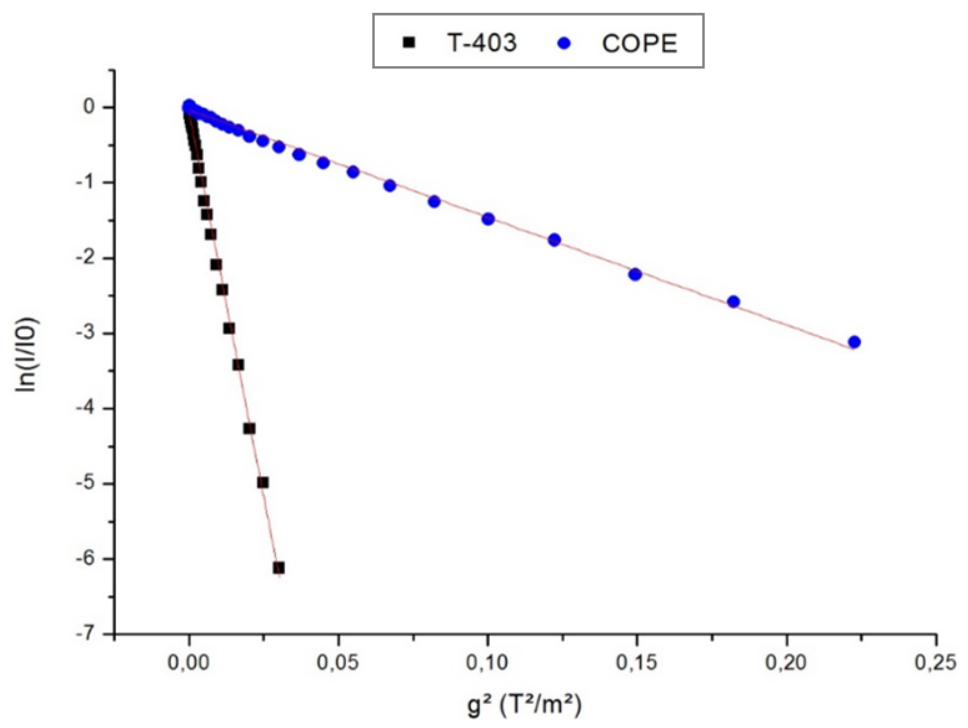

Figure 7: Logarithm of the normalized signal attenuation as a function of the gradient strength for the signals of interest of the non-reacted COPE + 10\%wt T-403 solution

As expected, two separated linear curves were obtained, illustrating the clear difference of diffusion behavior between the COPE and the T-403. Calculation of the diffusion coefficient from the slope of the curves gave the following values: $D_{\mathrm{T}}=2.4 \times 10^{-10} \mathrm{~m}^{2} . \mathrm{s}^{-1}$ and $\mathrm{D}_{\mathrm{C}}=1.7 \times 10^{-11} \mathrm{~m}^{2} . \mathrm{s}^{-1}$ for T-403 and COPE respectively, which is in agreement with the DOSY map measured average values of $\mathrm{D}_{\mathrm{T} 0}=3.3 \times 10^{-10} \mathrm{~m}^{2} \cdot \mathrm{s}^{-1}$ and $\mathrm{D}_{\mathrm{C} 0}=2.0 \times 10^{-11} \mathrm{~m}^{2} \cdot \mathrm{s}^{-1}$. This allowed us to differentiate the T-403 and COPE when no reaction is expected.

The 2D DOSY spectrum recorded on the COPE $+10 \%$ wt T-403 reactive blend obtained by reactive extrusion is shown in Figure 8. 


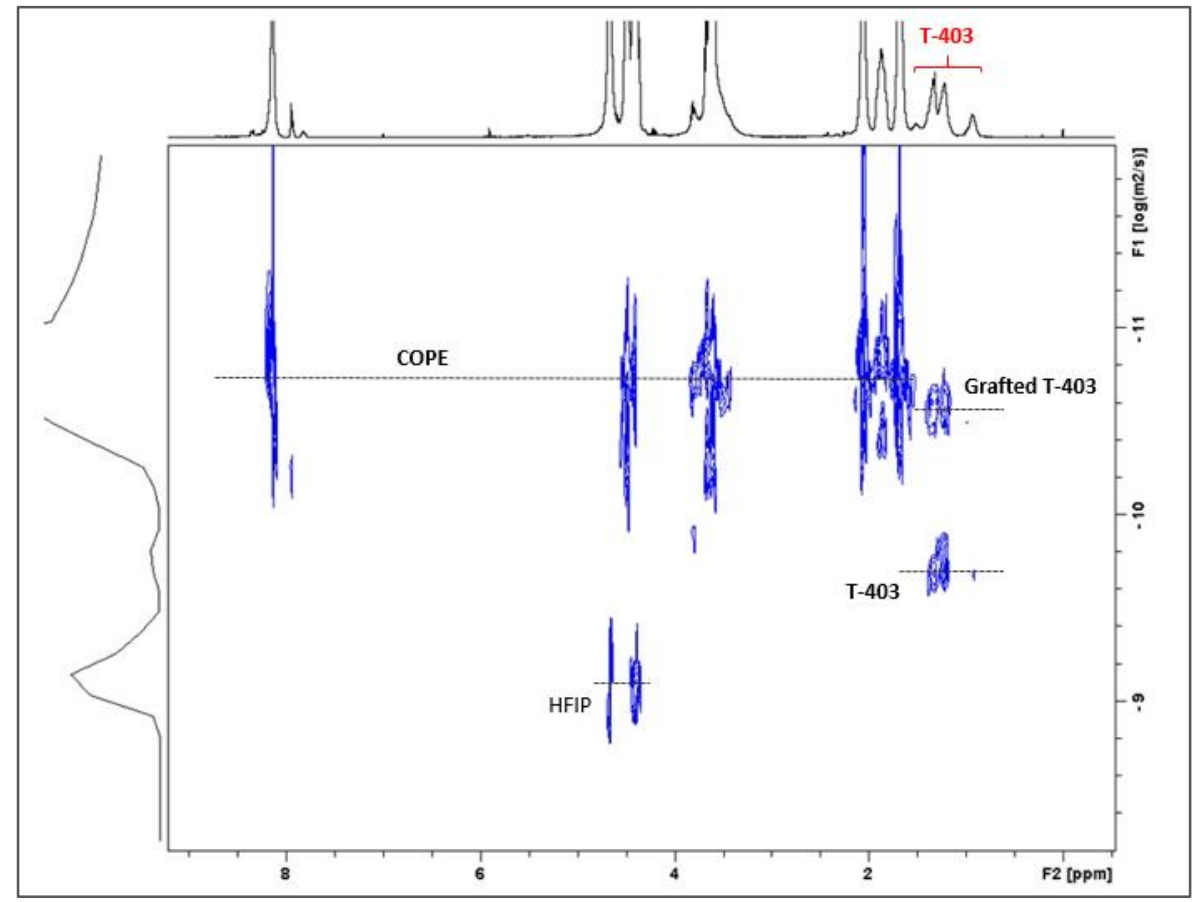

Figure 8: 2D DOSY spectrum of reacted COPE + 10\%wt T-403 blend in HFIP-d $\mathrm{d}^{2} / \mathrm{CDCl}_{3}(80: 20 \mathrm{v} / \mathrm{v})$.

We observe that the resolved NMR signals of the T-403 correlated with two different diffusion coefficients. The first one, measured at an average value $\mathrm{D}_{\mathrm{T} 1}=2.1 \times 10^{-10} \mathrm{~m}^{2} \cdot \mathrm{s}^{-1}$ is in good agreement with the average diffusion coefficient $\mathrm{D}_{\mathrm{T} 0}=3.3 \times 10^{-10} \mathrm{~m}^{2} . \mathrm{s}^{-1}$ obtained for free $\mathrm{T}-403$ in the non-reactive solution. The slight difference between $\mathrm{D}_{\mathrm{T} 1}$ and $\mathrm{D}_{\mathrm{T} 0}$ is mostly due to the small difference of concentration in the two NMR tubes which affects the viscosity of the sample and thus the diffusion of the species. Indeed diffusion coefficients of HFIP present the same difference. The second coefficient was measured at an average value $\mathrm{D}_{\mathrm{T} 2}=$ $2.4 \times 10^{-11} \mathrm{~m}^{2} \cdot \mathrm{s}^{-1}$ and corresponds to higher molar masses. The NMR signals of the COPE correlated with a wide range of diffusion coefficients including the coefficient $\mathrm{D}_{\mathrm{T} 2}$. This wide range of diffusion coefficients was larger than for the non-reacted COPE. It highlights a larger distribution of molar masses for the COPE resulting from the chain cleavage that happened during the reactive extrusion. The fact that the COPE and the T-403 NMR signals both correlated with the same average coefficient $\mathrm{D}_{\mathrm{T} 2}$ is the proof that a part of the $\mathrm{T}-403$ is actually linked to the COPE. This experiment thus confirms our interpretation of the ${ }^{13} \mathrm{C}$ spectra which highlighted the creation of amide covalent bonds by transamidification or condensation reactions during the reactive extrusion. The fact that the grafted T-403 correlated with a diffusion coefficient slightly lower than the average diffusion coefficient of the COPE can be an indication that the T-403 reacted preferentially with the smaller molar 
masses of COPE. But it also can indicate that the T-403 was mainly located at the COPE chain ends through the reaction of only one amine function per T-403 molecule ${ }^{25}$.

2D DOSY analysis were realized on the COPE $+8 \%$ wt M-600 and COPE $+4.5 \%$ wt D-400 blends and in both cases the NMR signals of the M-600 and the D-400 also correlated with two diffusion coefficients, corresponding to the reacted and the free compounds. The DOSY maps and the values of the diffusion coefficients obtained for these blends are shown in the

\section{Figure S5.}

The Stejskal-Tanner curves plotted for the T-403 NMR signals at 1.21 and $1.32 \mathrm{ppm}$, are presented in Figure 9 and compared to the corresponding curve for T-403 signals in the nonreacted blend.

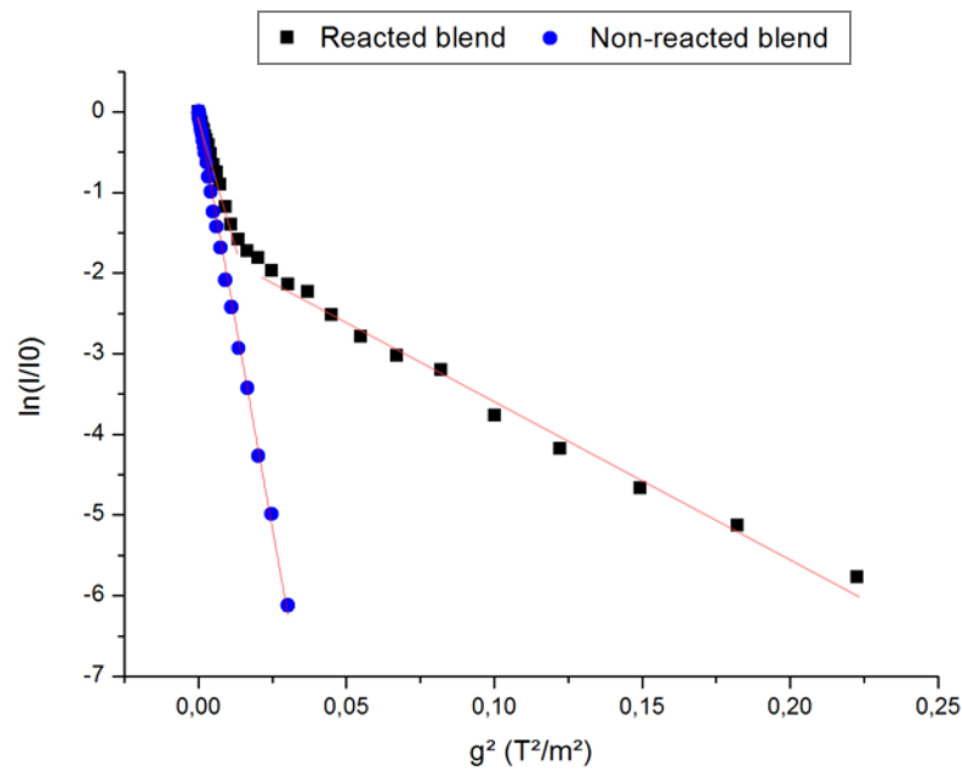

Figure 9: Logarithm of normalized signal attenuation as a function of the gradient strength for the signals of T403 in the reacted and non-reacted COPE $+10 \%$ wt T-403 blends

On the curve corresponding to the reacted blend and unlike what was observed for the nonreactive system, two different linear domains are observed. By linear fitting of these two domains, two diffusion coefficients were extracted ${ }^{24,26}$. The first one $D_{1}=1.5 \times 10^{-10} \mathrm{~m}^{2} \cdot \mathrm{s}^{-1}$ is of the same order of magnitude than the one calculated from the signal attenuation curve of the non-reacted system. The second coefficient $\mathrm{D}_{2}=2.3 \times 10^{-11} \mathrm{~m}^{2} \cdot \mathrm{s}^{-1}$ is very close to the COPE average diffusion coefficient measured for the sample without reaction $\left(\mathrm{D}_{\mathrm{C}}=1.7 \times 10^{-}\right.$ $11 \mathrm{~m}^{2} . \mathrm{s}^{-1}$ ) and was thus assigned to the T-403 linked to the COPE matrix. Those data confirmed the presence of two populations with average molar masses that differ by one order of magnitude but both containing a T-403 structure. 
Chain cleavage was highlighted by rheology and SEC analysis. The increase of Young's modulus at room temperature with the addition of T-403 suggests the creation of new domains with specific structures. Highlighted by the NMR results, these domains could be the consequence of the formation of star-shaped structures formed by a transamidification reaction between the amines of the T-403 and the ester groups of the COPE, and/or by a condensation of the amines on the acidic end-of-chain groups of the COPE, as shown in

\section{Figure 10.}

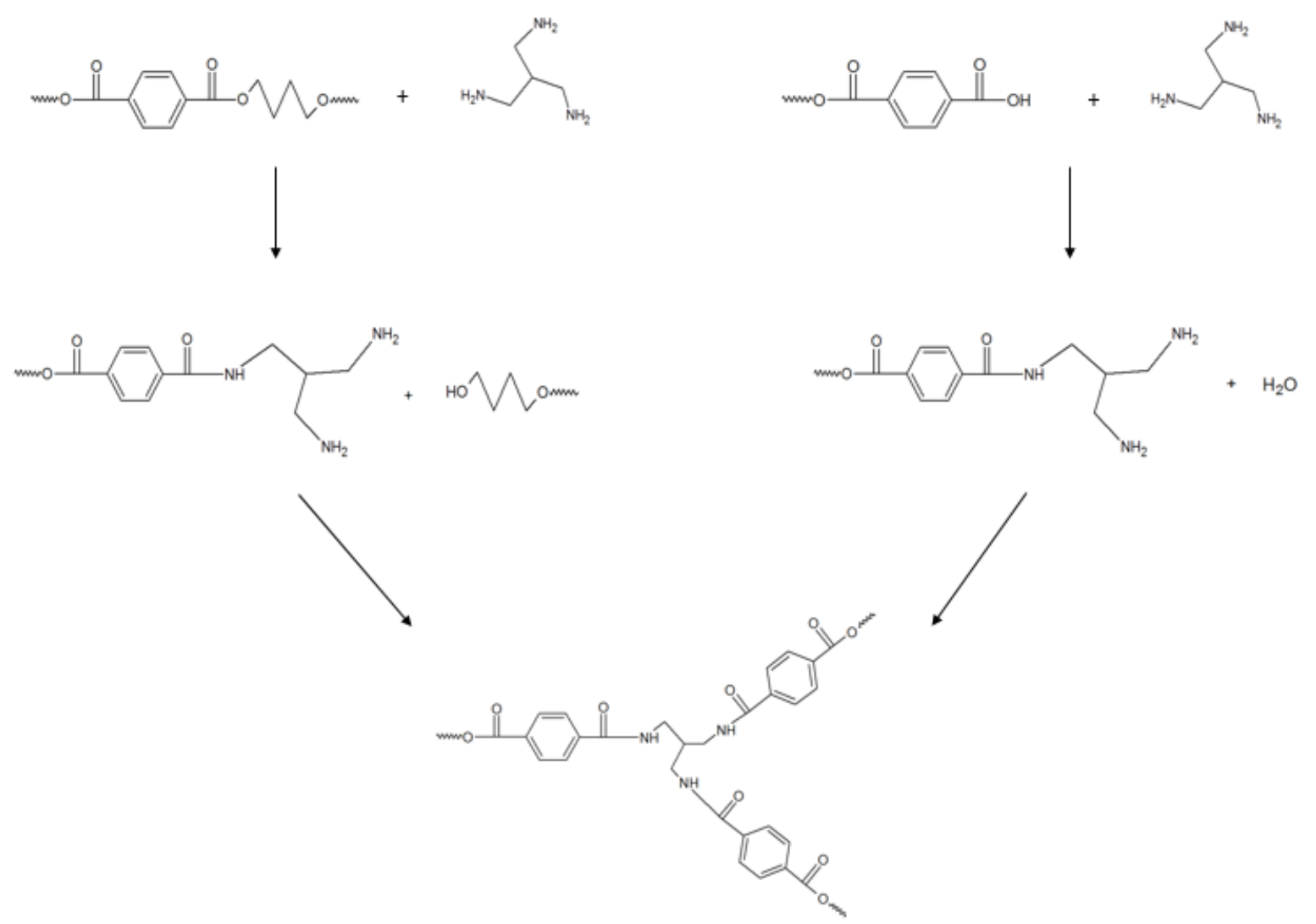

Figure 10: Transamidification/condensation reactions between COPE and T-403 leading to star-shaped structures

These 2D DOSY experiments allowed us to prove the covalent bond between T-403 and $\mathrm{COPE}$ and ${ }^{13} \mathrm{C}$ NMR showed that the reaction involved is the formation of amide functions. However, those analysis were unable to bring any information on the number of T-403 amino groups that reacted, and thus on the actual architecture of the formed structures.

\subsubsection{SEC-MALLS analysis}

To go further on the structure analysis of the COPE/T-403 reactive blends, 3 different samples were analyzed by SEC-MALLS: neat COPE, COPE + 3\%wt T-403 blend, and COPE 
$+8 \%$ wt M-600. SEC analysis of the COPE + M-600 blends showed that this additive causes a chain cleavage of the COPE, but its linear structure prevents any eventual branching to occur. COPE $+3 \%$ wt T-403 and COPE $+8 \%$ wt M-600 blends were specifically chosen because they present molar masses of the same orders, meaning that a chain cleavage of the same importance took place during the extrusion process for the two blends. Plots of the root mean square (RMS) radius versus the molar mass for these 3 samples are presented in Figure 11.

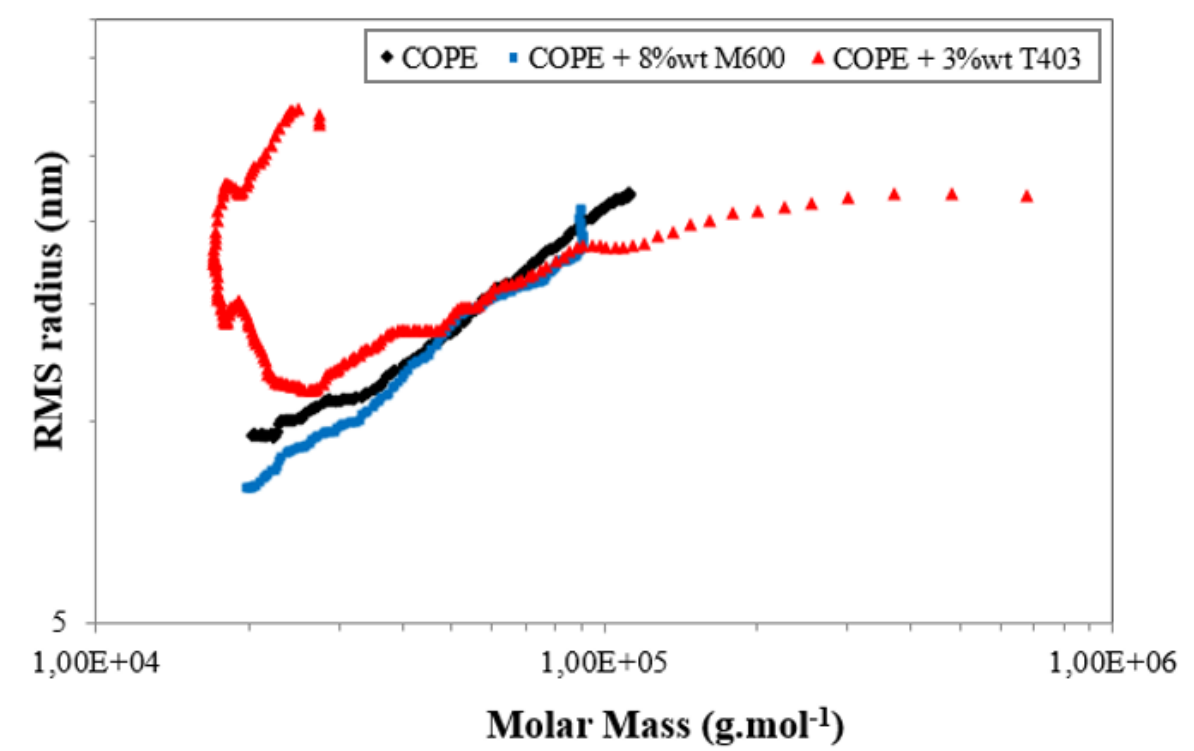

Figure 11: SEC-MALLS analysis of the COPE, the COPE + 8\%wt M-600 blend and the COPE + 10\%wt T-403 blend

We observe that for COPE and COPE + 8\%wt M-600 samples a similar plot shape with a linear curve, typical of linear polymer structures, was obtained. However, a non-linear shape was observed for the COPE $+3 \%$ wt T-403 sample. This kind of plot was already witnessed in the literature and shows that linear chains are not the only structures present in this sample. Different explanations have been advanced to explain this phenomenon: presence of microgels ${ }^{27}$, adsorption on the column, diffusion coefficients of the larger molecules too high to give a correct measure ${ }^{28}$, or an entanglement of branched molecules in the column ${ }^{28-31}$. The last hypothesis, known as the "Argentinean bolas effect", is the one that seems to correspond to our system. The entanglement of one chain from a star or double star-shaped molecule in the column packing would lead to a delay in the elution time of the polymer molecules presenting this kind of structure. So, after the normal decrease of the molar mass or RMS radius with increasing elution time, both curves curved up. This effect is more pronounced in the RMS radius versus elution time plot and results in a curvature of RMS radius versus molar mass as seen in Figure 11. 
However, if this typical curvature was observed many times, the explanation of this phenomenon is not fully understood and is still debated. Moreover, it was mainly witnessed on synthesized and well-defined branched polymers with high molar masses. Here, during the reactive extrusion process, the reaction of the amine on the copolyester blocks led to the formation of different polymer populations in the final material. Therefore, even if precautions must be taken on the interpretation of the SEC-MALLS measurements, they highlight once again structural differences between COPE/T-403 blends and linear COPE or COPE/M-600 blends.

\subsubsection{MALDI-TOF mass spectrometry}

In order to bring last complementary information about the structures created during the reaction between the COPE and the T-403, the soluble part of the COPE $+10 \%$ wt $\mathrm{T}-403$ blend obtained through a Soxlhet extraction was analyzed by MALDI-TOF mass spectrometry. The extractions were performed with refluxing ethanol. Drying of the extracted fraction was performed first on a rotary evaporator RC600 (KNF), and the last traces of solvent were removed from the samples with a Schlenk line. A wide variety of peaks was detected. Especially, different compounds resulting from the reaction of the three branches of the T-403 with PBT monomers or terephthalic acid were highlighted. The list of these compounds is presented in Table $\mathbf{4}$, and one of the detected molecules is presented as an example in Figure 12.

Table 4: PBT/Terephthalic acid grafted T-403 compounds detected in MALDI-TOF mass spectrometry in reflectron mode (dithranol matrix)

\begin{tabular}{|c|c|c|c|c|c|}
\hline n (T-403) & $\begin{array}{l}\text { Number of grafted } \\
\text { PBT monomer unit }\end{array}$ & $\begin{array}{l}\text { Number of grafted } \\
\text { terephthalic acid }\end{array}$ & $\begin{array}{c}\text { Chemical } \\
\text { formula }[\mathbf{M}+\mathbf{H}]^{+}\end{array}$ & $\begin{array}{c}\text { Monoisotopic } \\
\operatorname{mass}(\mathbf{m} / \mathbf{z})\end{array}$ & $\begin{array}{c}\text { Observed } \\
{[\mathbf{M}+\mathbf{H}]^{+}(\mathbf{m} / \mathbf{z})}\end{array}$ \\
\hline \multirow{3}{*}{3} & 1 & 2 & $\mathrm{C}_{43} \mathrm{H}_{56} \mathrm{~N}_{3} \mathrm{O}_{13}$ & 821.4 & 822.4 \\
\hline & 2 & 1 & $\mathrm{C}_{47} \mathrm{H}_{64} \mathrm{~N}_{3} \mathrm{O}_{14}$ & 893.4 & 894.4 \\
\hline & 3 & 0 & $\mathrm{C}_{51} \mathrm{H}_{72} \mathrm{~N}_{3} \mathrm{O}_{15}$ & 965.5 & 966.5 \\
\hline \multirow{3}{*}{4} & 1 & 2 & $\mathrm{C}_{46} \mathrm{H}_{62} \mathrm{~N}_{3} \mathrm{O}_{14}$ & 879.4 & 880.4 \\
\hline & 2 & 1 & $\mathrm{C}_{50} \mathrm{H}_{70} \mathrm{~N}_{3} \mathrm{O}_{15}$ & 951.5 & 952.5 \\
\hline & 3 & 0 & $\mathrm{C}_{54} \mathrm{H}_{78} \mathrm{~N}_{3} \mathrm{O}_{16}$ & 1023.5 & 1024.5 \\
\hline \multirow{3}{*}{5} & 1 & 2 & $\mathrm{C}_{49} \mathrm{H}_{68} \mathrm{~N}_{3} \mathrm{O}_{15}$ & 937.5 & 938.5 \\
\hline & 2 & 1 & $\mathrm{C}_{53} \mathrm{H}_{76} \mathrm{~N}_{3} \mathrm{O}_{16}$ & 1009.5 & 1010.5 \\
\hline & 3 & 0 & $\mathrm{C}_{57} \mathrm{H}_{84} \mathrm{~N}_{3} \mathrm{O}_{17}$ & 1081.6 & 1082.6 \\
\hline 6 & 1 & 2 & $\mathrm{C}_{52} \mathrm{H}_{74} \mathrm{~N}_{3} \mathrm{O}_{16}$ & 995.5 & 996.5 \\
\hline
\end{tabular}




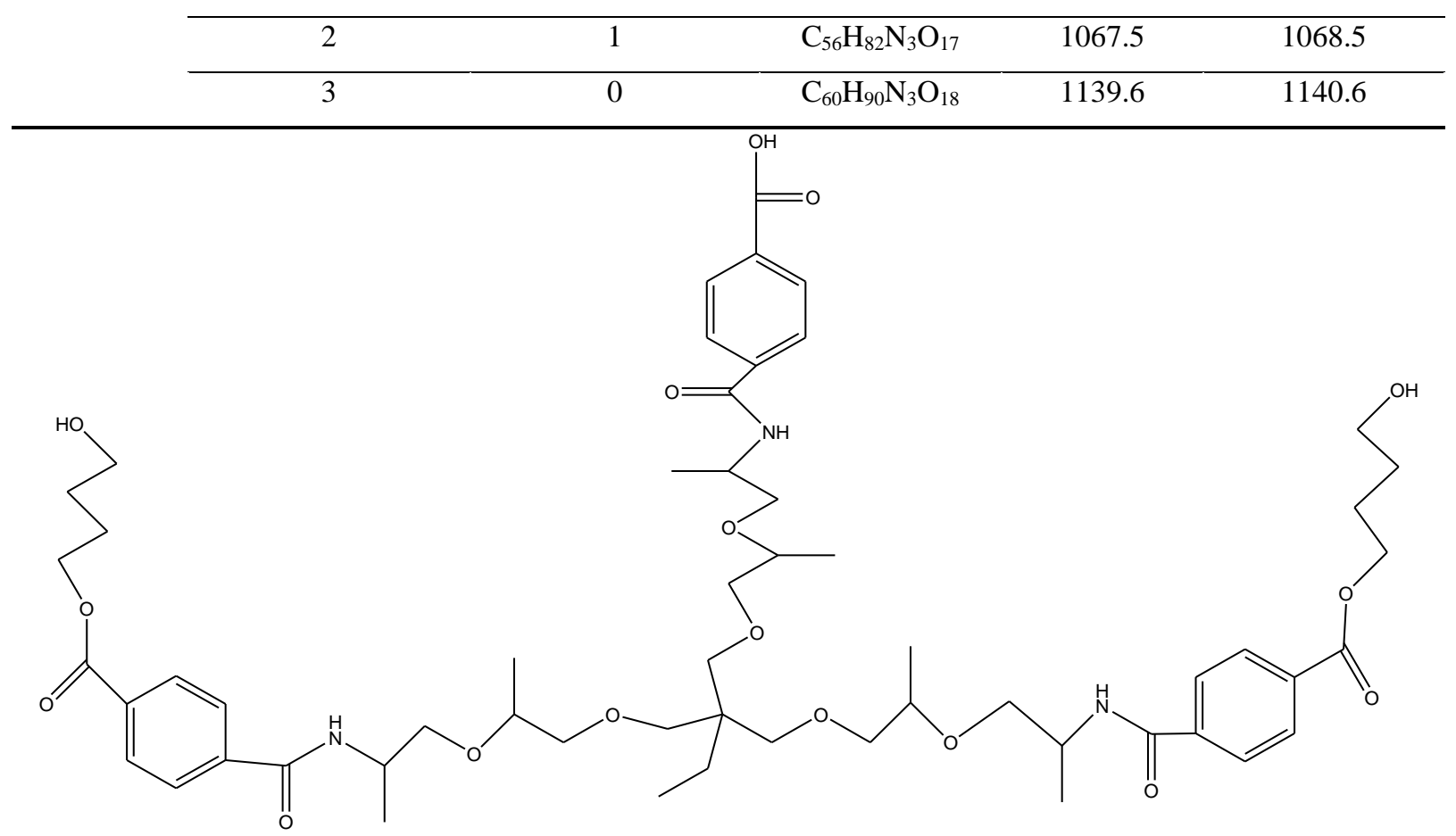

Figure 12: Structure of a T-403 macromolecule $(n=6)$ grafted by two PBT units and one terephthalic acid

The mass detection limit of the MALDI-TOF mass spectrometry technique did not allow us to observe hypothetical star-shape polymers with molar mass of several thousand g.mol $^{-1}$. However, the observation of such small star-shaped molecules is once again a solid contribution to the hypothesis that larger star-shaped structures are formed during the reactive extrusion of the COPE with T-403, leading to both a decrease of the viscosity and an enhancement of the mechanical properties. All these data are also in good agreement with our previous study dedicated to a polyamide- 6 structuration induced by its chemical reaction with a polyether triamine in the molten state ${ }^{32}$.

\section{Conclusion}

An increase of the Young's modulus up to 30\% coupled with a decrease of the viscosity (from $300 \mathrm{~Pa} . \mathrm{s}$ to $20 \mathrm{~Pa} . \mathrm{s}$ ) of the copolyether-ester COPE matrix was achieved through reactive extrusion with $2 \%$ wt of Jeffamine T-403.

The unique character of the T-403 on the properties of the COPE was highlighted by a comparative study with amine compounds having similar chemical functions but presenting different functionality and molar mass. Similar decrease of viscosity was obtained but no enhancement of the mechanical properties was witnessed for additives of the same molar 
mass with weaker functionality. Even for additives with higher molar mass, no remarkable effect neither on mechanical properties nor complex viscosity of the COPE were observed.

Different mechanisms occurring during the reactive extrusion have been studied. A chain scission caused by the reaction of the amino groups on the ester groups of the COPE was observed by SEC measurements. In the same time, grafting of the T-403 on the COPE was proved by 2D DOSY NMR analysis of the COPE/T-403 blends. MALLS and MALDI-TOF analysis of the blends as well as a comparison with COPE/monoamine and COPE/diamine blends allowed us to advance the hypothesis that this increase of mainly the Young's modulus properties coupled with an enhancement of the processability of the COPE is due to the creation of star-shaped structures with a T-403 core. Such structures will facilitate the flowability of the polymer in the molten state by avoiding chain entanglement while reinforce it in the solid state at room temperature. Such structures are not created with others mono or diamine and are in good agreement with behavior encountered in the literature for hyperbranched polymers.

Such results are very promising as it demonstrates that with a single reactive extrusion step, by a judicious selection of the triamine structure additive, a copolyether-ester based material presenting an enhancement of the Young's modulus and flowing properties can be developed.

\section{Acknowledgments}

The authors are grateful to the joint laboratory IMP/ HUTCHINSON for the financial support. The authors thank Flavien Mélis for his help for the extrusion and injection of the different blends, Catherine Ladavière for her help in MALDI-TOF mass spectrometry and her involvement in the interpretation of our results. This work has also benefited from the facilities and expertise of the Liquid Chromatography Platform (Institut de Chimie de Lyon) for the characterization of polymers.

\section{References}


1. Brienne, M. J.; Gabard, J.; Lehn, J. M.; Stibor, I. Journal of the Chemical SocietyChemical Communications Macroscopic expression of molecular recognition. Supramolecular liquid crystalline phases induced by association of complementary heterocyclic components 1989, (24), 1868-1870.

2. Fouquey, C.; Lehn J.-M.; Levelut, A.-M. Advanced Materials Molecular recognition directed self-assembly of supramolecular liquid crystalline polymers from complementary chiral components 1990, 2, (5), 254-257.

3. Yamauchi, K.; Lizotte, J. R.; Hercules, D. M.; Vergne, M. J.; Long, T. E. Journal of the American Chemical Society Combinations of Microphase Separation and Terminal Multiple Hydrogen Bonding in Novel Macromolecules 2002, 124, (29), 8599-8604.

4. Yamauchi, K.; Lizotte, J. R.; Long, T. E. Macromolecules Synthesis and Characterization of Novel Complementary Multiple-Hydrogen Bonded (CMHB) Macromolecules via a Michael Addition 2002, 35, (23), 8745-8750.

5. Yamauchi, K.; Lizotte, J. R.; Long, T. E. Macromolecules Thermoreversible Poly(alkyl acrylates) Consisting of Self-Complementary Multiple Hydrogen Bonding 2003, 36, (4), 1083-1088.

6. Yamauchi, K.; Kanomata, A.; Inoue, T.; Long, T. E. Macromolecules Thermoreversible Polyesters Consisting of Multiple Hydrogen Bonding (MHB) 2004, 37, (10), 3519-3522.

7. Elkins, C. L.; Viswanathan, K.; Long, T. E. Macromolecules Synthesis and Characterization of Star-Shaped Poly(ethylene-co-propylene) Polymers Bearing Terminal Self-Complementary Multiple Hydrogen-Bonding Sites 2006, 39, (9), 3132-3139.

8. Mather, B. D.; Elkins, C. L.; Beyer, F. L.; Long, T. E. Macromolecular Rapid Communications Morphological analysis of telechelic ureidopyrimidone functional hydrogen bonding linear and star-shaped poly(ethylene-co-propylene)s 2007, 28, (16), 1601-1606.

9. Agnaou, R.; Capelot, M.; Tence-Girault, S.; Tournilhac, F.; Leibler, L. Journal of the American Chemical Society Supramolecular Thermoplastic with $0.5 \mathrm{~Pa} \cdot \mathrm{s}$ Melt Viscosity 2014, 136, (32), 11268-11271.

10. Kim, Y. H.; Webster, O. W. Macromolecules Hyperbranched polyphenylenes 1992, $25,(21), 5561-5572$.

11. Hong, Y.; Cooper-White, J. J.; Mackay, M. E.; Hawker, C. J.; Malmstrom, E.; Rehnberg, N. Journal of Rheology A novel processing aid for polymer extrusion: Rheology and processing of polyethylene and hyperbranched polymer blends 1999, 43, (3), 781-793. 
12. Jang, J.; Oh, J. H.; Moon, S. I. Macromolecules Crystallization behavior of poly(ethylene terephthalate) blended with hyperbranched polymers: The effect of terminal groups and composition of hyperbranched polymers 2000, 33, (5), 1864-1870.

13. Mulkern, T. J.; Tan, N. C. B. Polymer Processing and characterization of reactive polystyrene/hyperbranched polyester blends 2000, 41, (9), 3193-3203.

14. Run, M. T.; Wang, J.; Yao, M.; Guo, L. J.; Wang, H. J.; Ba, X. W. Materials Chemistry and Physics Influences of hyperbranched poly(amide-ester) on the properties of poly(butylene succinate) 2013, 139, (2-3), 988-997.

15. Huber, T.; Potschke, P.; Pompe, G.; Hassler, R.; Voit, B.; Grutke, S.; Gruber, F. Macromolecular Materials and Engineering Blends of hyperbranched poly(ether amide)s and polyamide-6 2000, 280, (7-8), 33-40.

16. Lin, Y.; Zhang, K. Y.; Dong, Z. M.; Dong, L. S.; Li, Y. S. Macromolecules Study of Hydrogen-Bonded Blend of Polylactide with Biodegradable Hyperbranched Poly(ester amide) 2007, 40, (17), 6257-6267.

17. Kil, S. B.; Augros, T.; Leterrier, Y.; Manson, J. A. E.; Christel, A.; Borer, C. Polymer Engineering and Science Rheological properties of hyperbranched polymer/poly(ethylene terephthalate) reactive blends $\mathbf{2 0 0 3}, \mathbf{4 3}$, (2), 329-343.

18. Chabert, F.; Tournilhac, F.; Sajot, N.; Tence-Girault, S.; Leibler, L. International Journal of Adhesion and Adhesives Supramolecular polymer for enhancement of adhesion and processability of hot melt polyamides 2010, 30, (8), 696-705.

19. Samperi, F.; Puglisi, C.; Alicata, R.; Montaudo, G. Journal of Polymer Science Part aPolymer Chemistry Essential role of chain ends in the nylon-6/poly(ethylene terephthalate) exchange 2003, 41, (18), 2778-2793.

20. Johnson, C. S. Progress in Nuclear Magnetic Resonance Spectroscopy Diffusion ordered nuclear magnetic resonance spectroscopy: principles and applications 1999, 34, (3-4), 203-256.

21. Walderhaug, H.; Soderman, O.; Topgaard, D. Progress in Nuclear Magnetic Resonance Spectroscopy Self-diffusion in polymer systems studied by magnetic field-gradient spin-echo NMR methods 2010, 56, (4), 406-425.

22. Jerschow, A.; Muller, N. Journal of Magnetic Resonance Suppression of Convection Artifacts in Stimulated-Echo Diffusion Experiments. Double-Stimulated-Echo Experiments 1997, 125, (2), 372-375. 
23. Stejskal, E. O.; Tanner, J. E. Journal of Chemical Physics Spin Diffusion Measurements: Spin Echoes in the Presence of a Time-Dependent Field Gradient 1965, 42, (1), 288.

24. Sinnaeve, D., Concepts in Magnetic Resonance Part A The Stejskal-Tanner Equation Generalized for Any Gradient Shape-An Overview of Most Pulse Sequences Measuring Free Diffusion 2012, 40A(2) 39-65

25. Vieville, J.; Tanty, M.; Delsuc, M. A. Journal of Magnetic Resonance Polydispersity index of polymers revealed by DOSY NMR 2011, 212, (1), 169-173.

26. Jerschow, A.; Muller, N. Macromolecules Diffusion-Separated Nuclear Magnetic Resonance Spectroscopy of Polymer Mixtures 1998, 31, (19), 6573-6578.

27. Gores, F.; Johann, C.; Kilz, P. Abstracts of Papers of the American Chemical Society Copolymer Characterization using conventional SEC and molar mass sensitive detectors 1991, 202, 51 .

28. Frater, D. J.; Mays, J. W.; Jackson, C. Journal of Polymer Science Part B-Polymer Physics Synthesis and dilute solution properties of divinylbenzene-linked polystyrene stars with mixed arm lengths: Evidence for coupled stars 1997, 35, (1), 141-151.

29. Podzimek, S.; Vlcek, T.; Johann, C. Journal of Applied Polymer Science Characterization of branched polymers by size exclusion chromatography coupled with multiangle light scattering detector. I. Size exclusion chromatography elution behavior of branched polymers 2001, 81, (7), 1588-1594.

30. Gerle, M.; Fischer, K.; Roos, S.; Muller, A. H. E.; Schmidt, M.; Sheiko, S. S.; Prokhorova, S.; Moller, M. Macromolecules Main Chain Conformation and Anomalous Elution Behavior of Cylindrical Brushes As Revealed by GPC/MALLS, Light Scattering, and SFM 1999, 32, (8), 2629-2637.

31. Percec, V.; Ahn, C. H.; Cho, W. D.; Jamieson, A. M.; Kim, J.; Leman, T.; Schmidt, M.; Gerle, M.; Moller, M.; Prokhorova, S. A.; Sheiko, S. S.; Cheng, S. Z. D.; Zhang, A.; Ungar, G.; Yeardley, D. J. P. Journal of the American Chemical Society Visualizable cylindrical macromolecules with controlled stiffness from backbones containing libraries of self-assembling dendritic side groups 1998, 120, (34), 8619-8631.

32. Auclerc, M.; Tauleigne, A.; Da Cruz Boisson, F.; Vanhille Bergeronc, A.; Garois, N.; Fulchiron, R.; Sudre, G.; Cassagnau, P.; Bounor-Legaré, V. Polymer Polyamide-6 structuration induced by a chemical reaction with a polyether triamine in the molten state 2019, 172, 339-354 
Supporting Information.

Figure S1: NMR spectra of COPE, T-403 and COPE + 10\%wt T-403 blend

Figure S2 : Variation of the complex viscosity versus frequency for PBT/T-403 blends $\left(\mathrm{T}=220^{\circ} \mathrm{C}\right)$

Figure S3: AFM analysis of the COPE/T-403 blends

Figure S4: Comparison of the ${ }^{13} \mathrm{C}$ NMR spectra of the different COPE-Jeffamine blends Figure S5: 2D NMR DOSY spectra of the COPE/M-600 and COPE/D-400 blends

\section{Table of Contents graphic}

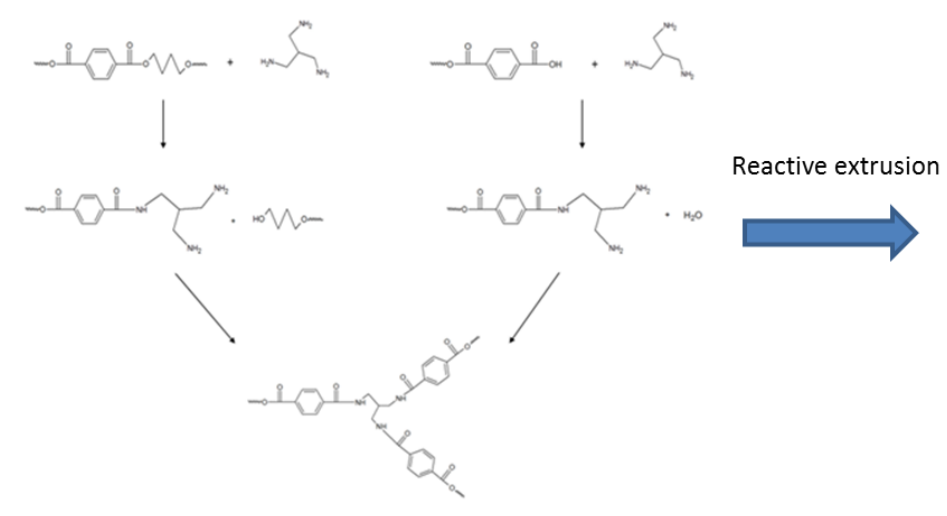

Decrease of the Viscosity vS

Increase of the Young Modulus 